\title{
The Differential Role of Premotor Frontal Cortex and Basal Ganglia in Motor Sequence Learning: Evidence From Focal Basal Ganglia Lesions
}

\author{
Cornelia Exner, ${ }^{1,3}$ Janka Koschack, ${ }^{2}$ and Eva Irle ${ }^{2}$ \\ ${ }^{1}$ Department of Clinical Psychology and Psychotherapy, University of Marburg, 35032 Marburg, Germany; ${ }^{2}$ Department of Psychiatry \\ and Psychotherapy, University of Göttingen, 37075 Göttingen, Germany
}

\begin{abstract}
There has been a growing interest in the differential role of various neural structures in implicit learning processes. The goal of our study was to clarify how focal lesions restricted to the basal ganglia interfere with different aspects of implicit visuo-motor sequence learning. A version of the Serial Reaction Time Task (SRTT) of Nissen and Bullemer using a 12-trial sequence was administered. A total of 20 subjects with focal basal ganglia lesions caused by ischemic or hemorrhagic infarction and 20 matched control subjects participated in this study. The results indicate that subjects with focal basal ganglia lesions showed unimpaired implicit learning of a 12-item motor sequence. Subjects with basal ganglia lesions, however, had more difficulties improving their general proficiency with the reaction-time task independent of sequence-specific learning. We observed a tendency toward smaller regional volumes in the cerebellum and left pre-supplementary motor area (pre-SMA) of subjects with basal ganglia lesions. Smaller cerebellar and pre-SMA volumes were related to lower implicit learning performance in the lesion group. The size of lesions in the basal ganglia was not related to sequence-specific implicit learning but had a significant influence on subjects' general proficiency for execution of the reaction-time task. We propose that implicit learning is achieved by a distributed network of cortical and subcortical structures. The basal ganglia seem to be responsible for adjusting to the general requirements of a task rather than for learning specific associations between stimuli that might be accomplished by premotor frontal areas and the cerebellum instead.
\end{abstract}

The process of successive adaptation of behavioral responses to contingencies in environmental stimuli has been called habit learning with respect to animal studies (Mishkin et al. 1984) and is thought to be mediated by a neural network comprising the basal ganglia, the frontal cortex, and the cerebellum. In humans this form of learning has been considered one among many forms of nondeclarative or implicit learning and has been contrasted to another form of learning that relies on the integrity of medial temporal lobe and diencephalic structures and is able to form conscious (declarative) associations between stimuli (Squire 1987).

The empirical evidence so far based on studies with brain-damaged subjects supports a role of the basal ganglia, the cerebellum, and the frontal cortex in the implicit acquisition of motor sequences. Most studies have focused on motor skill learning mainly by use of the Serial Reaction Time Task (SRTT) established by Nissen and Bullemer (1987). Subjects with degenerative basal ganglia diseases such as Parkinson's disease (PD; Ferraro et al. 1993; PascualLeone et al. 1993; Jackson et al. 1995; Doyon et al. 1997) and Huntington's disease (HD; Knopman and Nissen 1991)

${ }^{3}$ Corresponding author.

E-MAIL exnerc@mailer.uni-marburg.de; FAX +49 6421-2828904. Article and publication are at http://www.learnmem.org/cgi/doi/ $10.1101 / \mathrm{lm} .48402$ have been shown to be impaired on this implicit learning task. Subjects in later stages of PD, with bilateral involvement, or subjects with additional frontal type deficits were the most affected (Jackson et al. 1995; Doyon et al. 1997). However, there are also reports of preserved implicit learning of PD subjects in the SRTT (Smith et al. 2001). Even in those investigations that demonstrated less implicit learning in PD or HD subjects than in normal controls, basal ganglia subjects still showed a substantial decrease in reaction times in response to a repeating sequence and a slowing of responses when a random block was introduced. Thus, despite the disabling motor symptoms that accompany these diseases, subjects still demonstrated considerable procedural learning, although to a lesser extent than normal controls.

The interpretation of the findings mentioned above is problematic because the neuropathological changes and resulting symptoms in both Parkinson's and Huntington's disease are not restricted to the basal ganglia. Both diseases are frequently associated with structural and metabolic dysfunctions in frontal areas (Quinn et al. 1986; Aylward et al. 1998), which may themselves play a critical role in implicit learning, as has been demonstrated by studies in subjects with frontal lobe lesions (Jackson et al. 1995; Pascual-Leone et al. 1995, 1996; Ackermann et al. 1996; Gomez Beldarrain

LEARNING \& MEMORY 9:376-386 @ 2002 by Cold Spring Harbor Laboratory Press ISSN1072-0502/02 \$5.00

$$
\begin{array}{lllllllllllllll}
L & E & A & R & N & I & N & G & \mathbf{Q} & M & E & M & O & R & Y \\
\text { www.learnmem.org } & &
\end{array}
$$


et al. 1999). In functional imaging studies the primary motor and supplementary motor areas have been the structures most consistently shown to be activated when subjects learn to perform a sequential motor task (Grafton et al. 1995, 1998; Hazeltine et al. 1997).

In addition to the basal ganglia and the frontal cortex, the cerebellum has been proposed to form an important part of the neural network that supports the acquisition of new skills, especially motor skills. Several investigations have demonstrated reduced learning of motor sequences on the SRTT in subjects with degenerative or focal cerebellar lesions (Pascual-Leone et al. 1993; Doyon et al. 1997; Molinari et al. 1997; Gomez Beldarrain et al. 1998).

Although various subcortical, cortical, and cerebellar structures are involved in motor learning, their contributions to the learning processes might be different. This research is an effort to specify the role of the basal ganglia in motor sequence learning.

In the present investigation, 20 subjects with focal lesions in the basal ganglia (see Tables 1 and 2 for details; Fig. 1 for an example) were compared with a healthy control group ( $n=20$ ) on a modified version of the SRTT by Nissen and Bullemer (1987). The goals of our study were (1) to verify whether focal lesions restricted to the basal ganglia are able to interrupt implicit leaning of a visuo-motor sequence, (2) to establish which aspects of the implicit learning process are compromised by basal ganglia lesions, and (3) to analyze whether clinical characteristics such as size or lateralization of lesions and volume of different brain regions have an influence on implicit learning. We hypothesized that structural abnormalities or size of the supplementary motor cortex and the cerebellum, as well as basal ganglia lesion size would be related to deficits in implicit motor learning of subjects with basal ganglia lesions.

\section{RESULTS}

\section{Anatomical Results}

Absolute volume means for total brain and regional volumes can be seen from Table 3. The total brain volume was significantly larger in subjects with basal ganglia lesions $(P=0.029)$. All further analyses of regional volume differences were therefore adjusted for total brain volume. In the ANCOVA (analysis of covariance) model the regional differences between basal ganglia subjects and controls with regard to cerebellum and the left pre-SMA (pre-supplementary motor area) approached but did not quite reach conventional levels of significance $(P<0.1)$. There were no volume differences between groups for the right pre-SMA and the left and right SMA-proper (see Fig. 2 for parcellation).

\section{Behavioral Results: Serial Reaction Time Task (SRTT)}

\section{Comparison of Basal Ganglia Subjects and Controls}

The difference between the last sequence block 5 and the random block 6 was seen as the dependent variable for sequence-specific implicit learning. A nonparametric 2 $($ GROUP $) \times 2($ BLOCK) analysis comparing the basal ganglia group and the control group with repeated measures yielded a significant effect of BLOCK $\left(B_{(1)}=19.25 ; P<0.000\right)$. The GROUP effect was not significant $\left(B_{(1)}=1.79 ; P=0.18\right)$. There was no significant GROUP $\times$ BLOCK interaction $\left(B_{(1)}=0.35 ; P=0.55\right)$. Hotelling tests for each group re-

Table 1. Sociodemographic and Clinical Characteristics of Subjects

\begin{tabular}{|c|c|c|c|c|c|c|c|c|}
\hline \multirow[b]{2}{*}{ Variable $^{\mathrm{a}}$} & \multicolumn{3}{|c|}{ Group 1 (Basal ganglia) $n=20$} & \multicolumn{3}{|c|}{ Group 2 (Controls) $n=20$} & \multirow{2}{*}{$\frac{\text { Analysis }}{t \text {-Test } / \chi^{2}}$} & \multirow{2}{*}{$\frac{\text { Sig. }}{P}$} \\
\hline & M & & SD & M & & SD & & \\
\hline Age (years) & 53 & & 11 & 52 & & 9 & $t[38]=0.31$ & 0.757 \\
\hline Education (years) & 12 & & 2 & 13 & & 2 & $t[38]=-1.25$ & 0.219 \\
\hline WAIS-R: Full-scale IQ & 100 & & 18 & 111 & & 18 & $t[38]=-1.95$ & 0.059 \\
\hline Sex (female:male) & & $3: 17$ & & & $5: 15$ & & $\chi^{2}[1]=1.57$ & 0.21 \\
\hline Stroke symptom onset (months) & 24 & & 14 & & & & & \\
\hline Lesion size $(\mathrm{mL})$ & 1.5 & & 1.9 & & & & & \\
\hline Etiology of lesion (ischemia: hemorrhage) & & $15: 5$ & & & & & & \\
\hline Laterality of lesion (right:left:bilateral) & & $9: 9: 2$ & & & & & & \\
\hline Motor abnormalities ${ }^{\mathrm{b}}$ (none:mild:moderate) & & $13: 3: 4$ & & & & & & \\
\hline Incoordination ${ }^{\mathrm{c}}$ (none:mild:moderate) & & $14: 3: 3$ & & & & & & \\
\hline
\end{tabular}

Table values are given as mean $(\mathrm{M})$ and standard deviation (SD) unless otherwise indicated.

${ }^{b}$ Mild symptoms included mild facial or limb weakness and alternations of muscle bulk or tone. Moderate symptoms included residual signs of hemiparesis.

cMild symptoms included dysdiadochokinesis, mild dysmetria, or mild abnormalities of stance and gait. Moderate symptoms included moderate ataxia or dysmetria.

WAIS-R: Wechsler Adult Intelligence Scale-Revised. IQ estimates were derived from Information, Similarities, Picture Completion, and Block Design Scores.

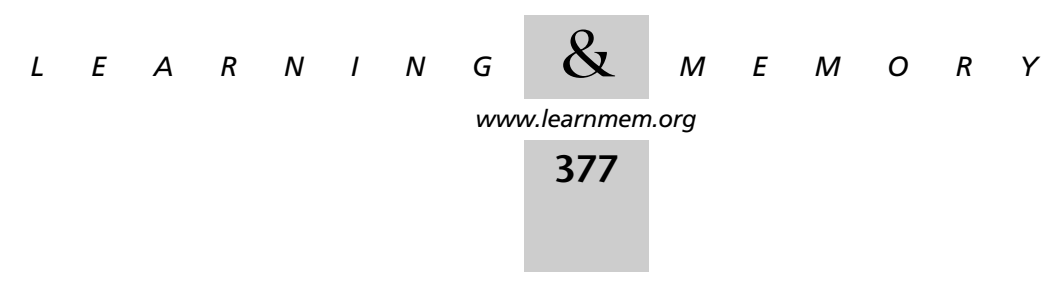


Table 2. Lesion Characteristics and SRTT Performance in Subjects with Basal Ganglia Lesions

\begin{tabular}{|c|c|c|c|c|c|c|c|}
\hline \multirow[b]{2}{*}{$\begin{array}{l}\text { Subject } \\
\text { number }\end{array}$} & \multicolumn{5}{|c|}{ Lesion characteristics } & \multicolumn{2}{|c|}{ SRTT performance } \\
\hline & Lesion side & $\begin{array}{c}\text { Lesion } \\
\text { volume }(\mathrm{mL})\end{array}$ & $\begin{array}{l}\text { Caudate } \\
\text { nucleus }\end{array}$ & Putamen & $\begin{array}{c}\text { Lacunar lesion } \\
\text { in BA } 4 \text { or } 6\end{array}$ & $\begin{array}{l}\text { Implicit } \\
\text { learning }\end{array}$ & $\begin{array}{l}\text { General reaction- } \\
\text { time improvement }\end{array}$ \\
\hline 130 & Right & 1.0 & ++ & ++ & + & -81 & 53 \\
\hline $108^{\mathrm{b}}$ & Right & 0.4 & 0 & + & + & -53 & 224 \\
\hline 111 & Right & 5.4 & + & +++ & + & -33 & -67 \\
\hline 110 & Left & 0.5 & ++ & 0 & + & -12 & 184 \\
\hline $107^{a, b}$ & Bilateral & 0.9 & 0 & $++/+$ & + & -8 & 149 \\
\hline 103 & Right & 0.4 & 0 & + & 0 & 9 & 198 \\
\hline 101 & Right & 0.1 & 0 & + & 0 & 24 & 3 \\
\hline 105 & Right & 0.5 & + & 0 & + & 26 & 32 \\
\hline $106^{\mathrm{b}}$ & Left & 3.3 & ++ & +++ & + & 32 & -100 \\
\hline 131 & Left & 0.9 & + & ++ & 0 & 38 & 52 \\
\hline 102 & Right & 1.4 & ++ & + & 0 & 40 & 13 \\
\hline 137 & Left & 0.5 & + & + & 0 & 50 & 19 \\
\hline 120 & Left & 2.1 & +++ & +++ & 0 & 52 & -29 \\
\hline 109 & Right & 0.2 & 0 & + & 0 & 55 & 139 \\
\hline 140 & Left & 1.9 & 0 & +++ & 0 & 56 & -55 \\
\hline 116 & Left & 7.2 & +++ & +++ & 0 & 57 & -66 \\
\hline $133^{a, b}$ & Bilateral & 0.3 & $+/+$ & $+/+$ & 0 & 63 & -48 \\
\hline 134 & Left & 1.5 & + & +++ & 0 & 67 & -94 \\
\hline 121 & Left & 1.2 & ++ & ++ & 0 & 75 & 3 \\
\hline 118 & Right & 0.6 & 0 & ++ & 0 & 103 & -33 \\
\hline
\end{tabular}

$\mathrm{BA}=$ Brodmann area; $\mathrm{SRTT}=$ Serial Reaction Time Task; SMA = supplementary motor area; 0 = no lesion; $+=$ small lesion; $++=$ moderately sized lesion; $+++=$ large lesion.

Implicit Learning: reaction time difference $(\mathrm{ms})$ between blocks 6 and 5. General Reaction-Time Improvement: reaction time difference (ms) between blocks 1 and 6 .

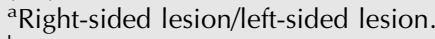

${ }^{b}$ Mild diffuse cortical atrophy or moderately enlarged lateral ventricle.

Lesions of the caudate nucleus covered in most cases head and body of the caudate (subject nos. 130, 111, 105, 106, 102, 137, 120,

116,133 , and 134), but were restricted in three subjects (nos. 110, 131, and 121) to the head of the caudate.

vealed significant differences between the two blocks in the basal ganglia group (mean reaction time difference: 28

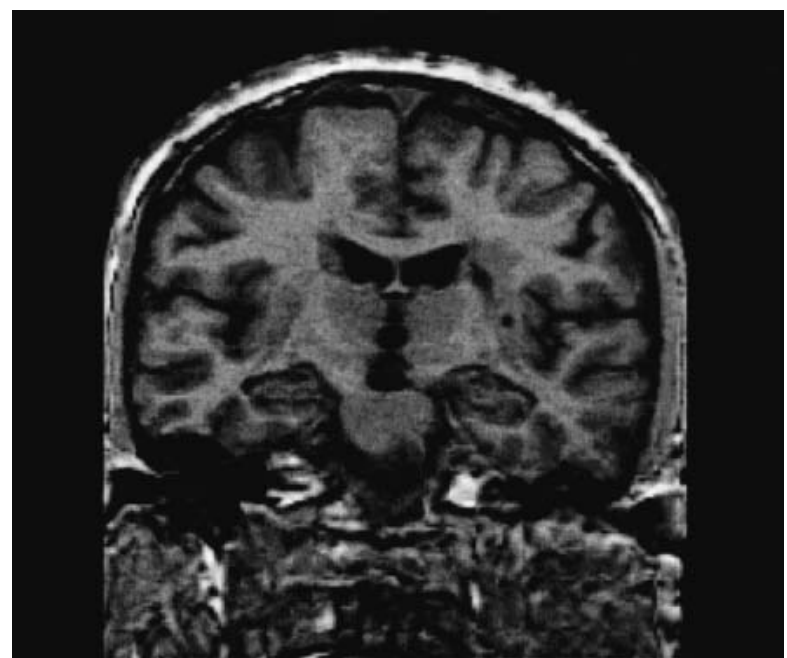

Figure 1 Magnetic resonance scan of subject no. 102 of the basal ganglia group, showing an infarction involving parts of both the caudate nucleus and the putamen. msec; $\left.F_{(1,19)}=7.91 ; P=0.011\right)$ and in the control group (mean reaction time difference: $48 \mathrm{msec} ; F_{(1,19)}=16.66$; $P=0.001$ ), demonstrating significant implicit learning in both groups.

Second, we compared groups with regard to the difference between the two random blocks 1 and 6 (general reaction-time improvement) reflecting generalized skill learning that is due to a subject's growing proficiency with the requirements of the task independent of sequence-specific learning. A nonparametric 2 (GROUP) $\times 2$ (BLOCK) analysis comparing the basal ganglia group and the control group with repeated measures between the two random blocks 1 and 6 revealed a significant effect of BLOCK $\left(B_{(1)}=8.97 ; P=0.003\right)$ but not GROUP $\left(B_{(1)}=0.91\right.$; $P=0.34)$. The GROUP $\times$ BLOCK interaction just missed the conventional level of significance $\left(B_{(1)}=3.06 ; P=0.08\right)$. Hotelling tests for each group revealed significant differences between the two blocks only in the control group (mean reaction time difference: $29 \mathrm{msec} ; F_{(1,19)}=9.25$; $P=0.007)$. In the basal ganglia group no significant decrease of response latencies between block 1 and block 6 occurred (mean reaction time difference: 49 msec; $\left.F_{(1,19)}=0.99 ; P=0.33\right)$.

$$
\begin{array}{lllllllllllllll}
L & E & A & R & N & I & N & G & \& & M & E & M & O & R & Y \\
\text { www.learnmem.org } & &
\end{array}
$$


Table 3. Brain Volume Measures of Subjects

\begin{tabular}{|c|c|c|c|c|c|c|}
\hline & \multicolumn{2}{|c|}{$\begin{array}{c}\text { Group } 1 \\
\text { (Basal ganglia) } n=16^{\mathrm{a}}\end{array}$} & \multicolumn{2}{|c|}{$\begin{array}{c}\text { Group } 2 \\
\text { (Controls) } n=13^{\mathrm{b}}\end{array}$} & \multirow{2}{*}{$\frac{\text { Analysis }}{t \text {-Test/ANCOVA }}$} & \multirow{2}{*}{$\frac{\text { Sig. }}{P}$} \\
\hline & M & SE & M & SE & & \\
\hline Total brain volume $(\mathrm{mL})$ & 1253 & 33 & 1128 & 45 & $t[27]=2.31$ & 0.029 \\
\hline Cerebellar volume $(\mathrm{mL})^{\mathrm{c}}$ & 117.4 & 1.8 & 122.4 & 2.1 & $F[1 ; 26]=3.09$ & 0.091 \\
\hline Pre-SMA, left ${ }^{\mathrm{C}}$ & 10.5 & 0.4 & 11.7 & 0.5 & $F[1 ; 26]=3.13$ & 0.089 \\
\hline Pre-SMA, right ${ }^{c}$ & 11.3 & 0.6 & 11.4 & 0.7 & $F[1 ; 26]=0.02$ & 0.895 \\
\hline SMA-proper, left ${ }^{\mathrm{c}}$ & 10.4 & 0.7 & 10.6 & 0.8 & $F[1 ; 26]=0.05$ & 0.834 \\
\hline SMA-proper, right ${ }^{\mathrm{C}}$ & 10.4 & 0.7 & 12.1 & 0.8 & $F[1 ; 26]=2.63$ & 0.117 \\
\hline
\end{tabular}

(M) Mean, (SE) standard error of mean, (SMA) supplementary motor area, (ANCOVA) analysis of covariance with total brain volume as a covariate.

${ }^{a}$ Brain volume measures were only available for 16 subjects of the basal ganglia group. Five of the seven subjects with additional lacunar lesions in frontal motor areas (including supplementary motor area) (cf. Fig. 2A, Materials and Methods, Lesion Analysis and Lesion Groups) are included in this group.

${ }^{\mathrm{b}}$ Brain volume measures were only available for 13 subjects of the control group.

'Mean values adjusted for total brain volume.

\section{Explicit Knowledge}

Using separate two-tailed $t$-tests the mean explicit knowledge score of each group was compared with the random level $(M=39.6, \mathrm{SD}=6.5)$. None of the groups scored significantly above random level. Only one subject of the basal ganglia group and three subjects of the control group scored more than 1 SD above the mean of the random level, indicating that these subjects possibly had acquired a significant amount of explicit knowledge about the repeated sequence. The amount of explicit knowledge of the sequence was, however, not significantly correlated to implicit learning in the basal ganglia $(r=0.25 ; P=0.30)$ or the control group $(r=0.11 ; P=0.66)$, indicating an independence of implicit and explicit acquisition of the sequence.

To summarize (also see Fig. 3A), both the basal ganglia group and the control group showed a decrease of response latencies across blocks 1 to 5 . When stimuli were again presented in a random order, a significant increase of re-

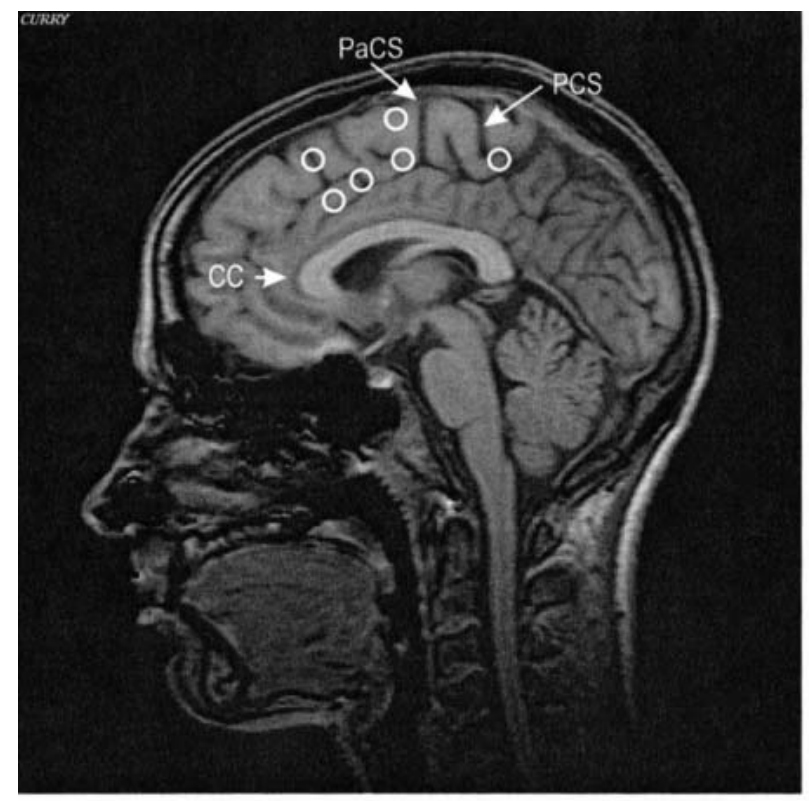

A

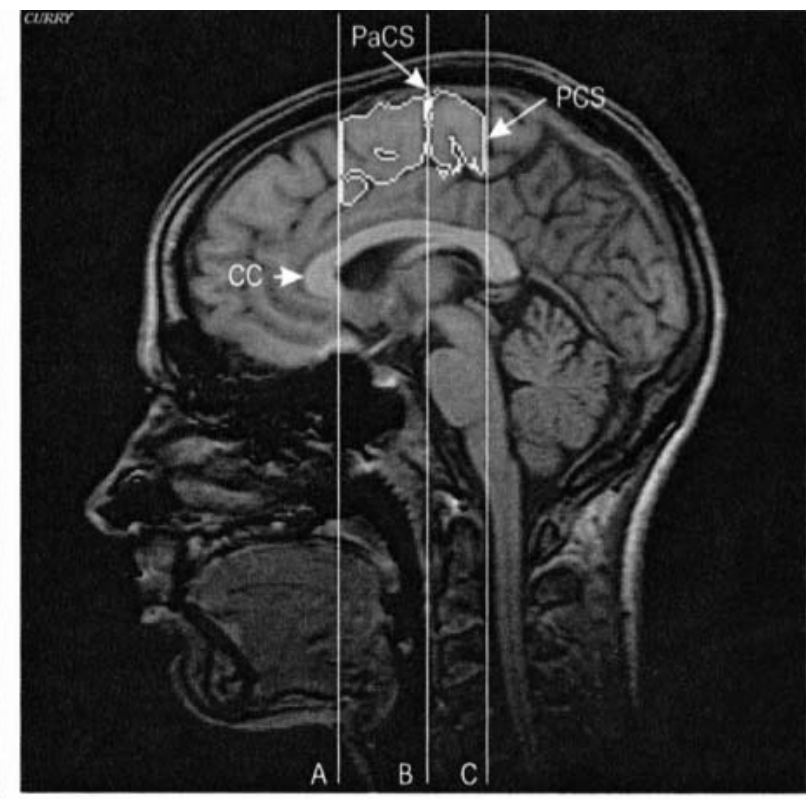

B

Figure 2 (A) Schematic representation of lesion location in the subgroup of basal ganglia subjects (group 1A) with additional lesions in frontal motor areas superimposed on a sagittal slice of a control subject and $(B)$ sagittal slice of the same control subject showing segmented volumes of the pre-SMA and SMA-proper; (Pre-SMA) plane A-plane B; (SMA-proper) plane B-plane C; (CC) corpus callosum; (PaCS) paracentral sulcus; (PCS) medial part of the precentral sulcus.

$$
\begin{array}{lllllllllllllll}
L & E & A & R & N & I & N & G & \mathcal{Q} & M & E & M & O & R & Y \\
\text { www.learnmem.org } & & & & &
\end{array}
$$



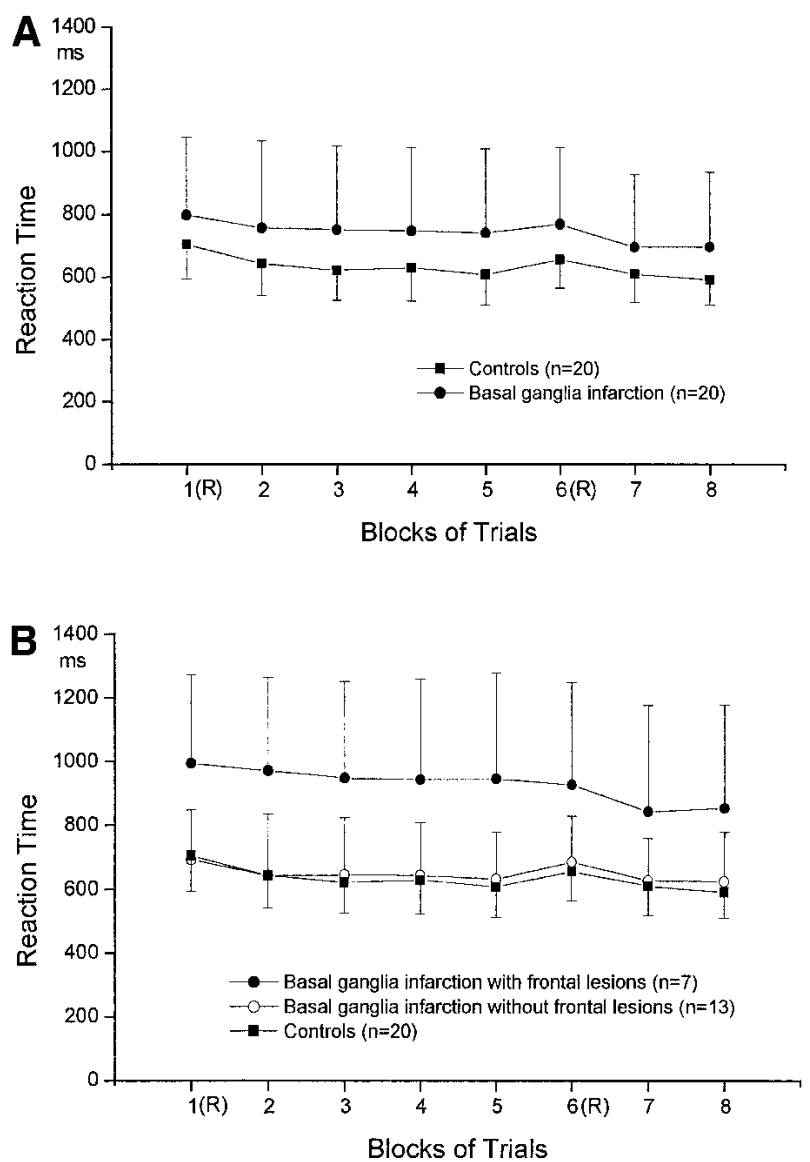

Figure 3 (A) Mean reaction times across blocks of basal ganglia subjects and controls in the SRTT. In blocks 1 and 6 the sequence of stimuli was random (R). Block 2-5, 7, and 8 contained a 12 -item repeating sequence. $(B)$ Mean reaction times across blocks of basal ganglia subjects with (group 1A) and without (group 1B) frontal lacunar lesions and control subjects.

sponse times in block 6 occurred in the basal ganglia and the control group, demonstrating implicit learning of the embedded sequence. Subjects with basal ganglia lesions responded slower than controls, but there were no significant differences between groups in the amount of implicit learning in the SRTT. The basal ganglia group showed less general reaction-time improvement than the control group, indicated by a lack of significant reaction-time improvement between the two random blocks 1 and 6 . None of the two study groups acquired explicit knowledge of the sequence that exceeded chance level.

\section{Comparison of Basal Ganglia Subjects With and Without Frontal Lesions}

A nonparametric 3 (GROUP) $\times 2$ (BLOCK) analysis comparing subjects with additional frontal lesions $(n=7$; group 1A) to those without frontal lesions ( $n=13$; group $1 \mathrm{~B})$ and to control subjects $(n=20)$ across blocks 5 and 6 (implicit learning) yielded a significant effect of BLOCK
$\left(B_{(1)}=27.59 ; P=0.000\right)$ and a significant GROUP $\times$ BLOCK interaction $\left(B_{(1.38)}=12.49 ; P=0.001\right)$. The effect of GROUP just missed the conventional level of significance $\left(B_{(1.52)}=4.23 ; P=0.076\right)$. Hotelling tests for the two basal ganglia subgroups revealed significant differences between the two blocks in the group of subjects without frontal lesions (mean reaction time difference: 53.0 msec; $\left.F_{(1,12)}=45.25 ; P=0.000\right)$. Subjects with lacunar frontal lesions showed no slowing of response times when the random block was introduced, demonstrating no significant implicit learning of the sequence (see Fig. 3B; mean reaction time difference: $\left.-18.4 \mathrm{msec} ; F_{(1,6)}=1.86 ; P=0.22\right)$.

A nonparametric 3 (GROUP) $\times 2$ (BLOCK) analysis comparing groups $1 \mathrm{~A}, 1 \mathrm{~B}$, and the control group between the two random blocks 1 and 6 (general reaction-time improvement) yielded a significant effect of BLOCK $\left(B_{(1)}=6.95 ; P=0.008\right)$. The GROUP effect just missed the conventional level of significance $\left(B_{(1.54)}=4.78\right.$; $P=0.058)$, and the GROUP $\times$ BLOCK interaction was not significant $\left(B_{(1.95)}=2.98 ; P=0.22\right)$. However, Hotelling tests indicated that neither in basal ganglia subjects without frontal lesions (mean reaction time difference: $7.8 \mathrm{msec}$; $\left.F_{(1,12)}=0.08 ; P=0.78\right)$ nor in those with frontal lesions (mean reaction time difference: $67.9 \mathrm{msec} ; F_{(1,6)}=1.84$; $P=0.22)$ did a significant decrease of response latencies between blocks 1 and block 6 occur (see Fig. 3B).

\section{Influence of Lateralization of Basal Ganglia Lesions}

No significant differences emerged between subjects with right-sided and subjects with left-sided lesions in the basal ganglia with regard to implicit learning and general reaction-time improvement on two subsequent GROUP (2) $\times$ BLOCK (2) nonparametric analyses. Subjects with right and left basal ganglia lesions also did not differ with regard to the explicit knowledge of the repeated sequence they acquired.

\section{Influence of Basal Ganglia Lesion Size}

Basal ganglia lesion size was not significantly related to implicit learning $(r=-0.04 ; P=0.87)$ or explicit knowledge $(r=-0.19 ; P=0.43)$. However, lesion size in the basal ganglia was significantly related to general reaction-time improvement $(r=-0.52 ; P=0.022)$. Subjects with larger lesions showed less reaction time improvement (see Fig. 4).

\section{Influence of Regional Brain Volumes}

Cerebellar volume and volume of the left pre-SMA were significantly related to sequence-specific implicit learning in the basal ganglia group. Subjects with larger volumes of the left pre-SMA $(r=0.56 ; P=0.029)$ and larger cerebellar volumes $(r=0.73 ; P=0.002)$ showed better implicit learning in the SRTT (see Fig. 4). The volumes of the right pre-SMA $(r=0.23 ; P=0.38)$ and the right $(r=0.22 ; P=0.41)$ and left ( $r=0.26 ; P=0.34)$ SMA-proper were not significantly related to sequence-specific implicit learning. Relationships

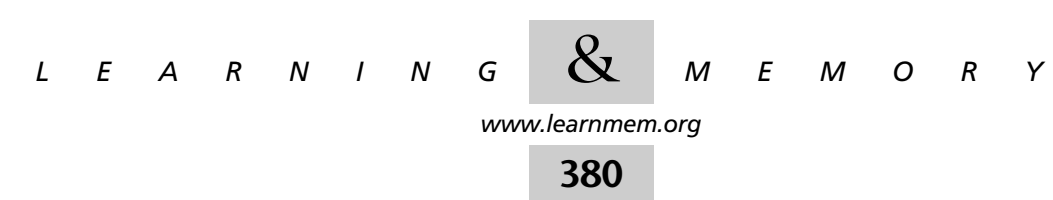



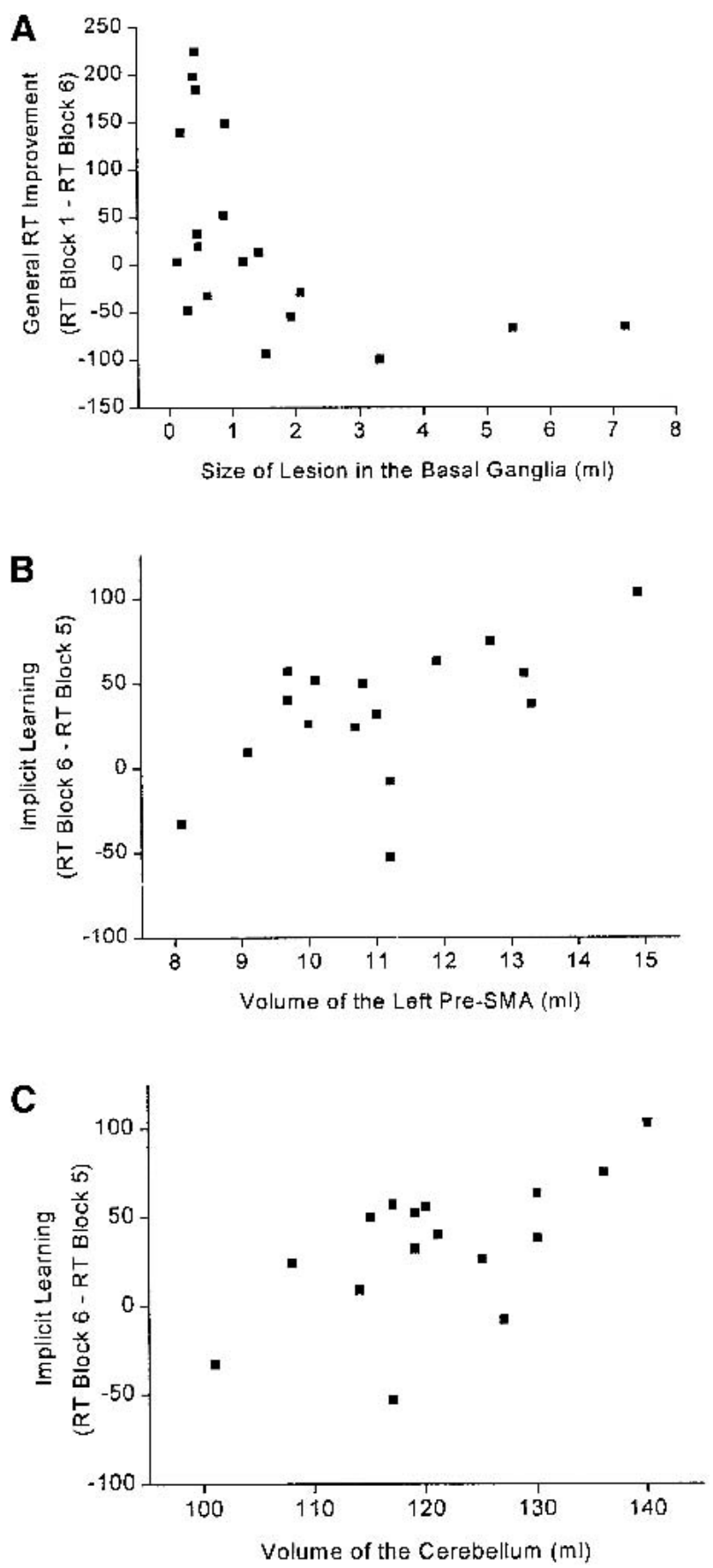

Figure 4 (A) Relationship between lesion size in the basal ganglia and general RT improvement in the SRTT $(r=-0.52 ; P=0.022)$ for the basal ganglia group. $(B)$ Relationship between volume of the left pre-SMA and sequence-specific implicit learning in the SRTT $(r=0.56 ; P=0.029$; partial correlation coefficient adjusted for total brain volume) for the basal ganglia group. (C) Relationship between volume of the cerebellum and sequence-specific implicit learning in the SRTT $(r=0.73 ; P=0.002$; partial correlation coefficient adjusted for total brain volume) for the basal ganglia group. between regional brain volumes and explicit knowledge or general reaction-time improvement in the basal ganglia group were all not significant.

\section{DISCUSSION}

\section{Summary of Findings}

In the present investigation we found that subjects with focal basal ganglia lesions as a group were as able as healthy controls to achieve implicit learning of a visuo-motor sequence (Fig. 3A). Unlike the control group, however, they showed no significant general reaction-time improvement between random blocks. None of the groups acquired explicit knowledge of the motor sequence above chance level, demonstrating independence on implicit and explicit learning processes. Lateralization of lesion had no influence on implicit learning in the basal ganglia group. Larger lesions in the basal ganglia had a deteriorating influence on subjects' general proficiency for execution of the reactiontime task (general reaction-time improvement) but was not related to sequence-specific implicit learning in the SRTT (Fig. 4A). Sequence-specific implicit learning in the SRTT was significantly influenced by cerebellar volume and left pre-SMA volume in subjects with basal ganglia lesions (Fig. $4 B, C)$. Subjects with additional lacunar frontal lesions in the basal ganglia group showed no implicit learning in contrast to basal ganglia subjects without additional frontal lesions (Fig. 3B).

\section{Implicit Sequence Learning Versus General Reaction-Time Improvement in Basal Ganglia Disease}

We propose that there are two different processes involved that lead to reaction-time gains in the SRTT: (1) general reaction-time improvement that is due to subjects' growing proficiency with the requirements of the task independent of the existence of an embedded sequence and that can be seen from the difference between random blocks; and (2) sequence-specific implicit learning indicated by the reaction-time difference between the last sequence block and the random block. Greater proficiency with the requirements of this conditioned response task could be achieved independent of an underlying sequence as subjects become more and more fluent in matching the appropriate motor response to the visual stimuli and in switching between the four alternative responses (stimulus-response matching). The existence of a repeated sequence in the stimuli and responses would allow further reaction-time improvement owing to anticipatory direction of visual attention and growing automaticity of motor response chains. These two latter processes might be involved in sequence-specific implicit learning.

In our study, the significant negative correlation between basal ganglia lesion size and reaction-time gains be-

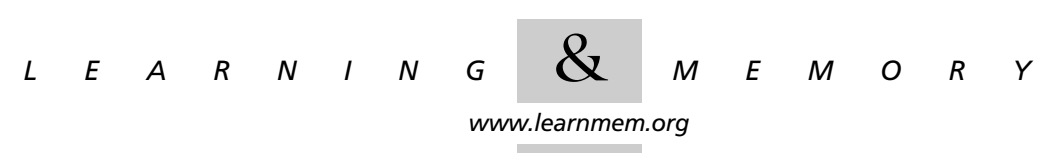


tween random blocks indicates that the basal ganglia are mainly involved in those adaptive processes that underlie general reaction-time improvement independent of specific sequence learning. This is in line with findings by other researchers that could show that subjects in the later (bilateral) stages of Parkinson's disease had difficulties on a random version of the SRTT (Laforce and Doyon 2001). Singh et al. (1993) reported increased cerebral blood flow in the striatum and thalamus while healthy subjects were executing a random condition of the SRTT. The tasks used in these two investigations could figure as models of motor learning due to pure general reaction-time improvement. The deficits of PD subjects on this task and the increased activity of the striatum when normal subjects perform the random SRTT are consistent with a prominent role of the basal ganglia in the development of perceptual-motor programs based on stimulus-response associations.

Our study further showed that deficits in implicit learning of the embedded sequence were not related to the presence or size of basal ganglia lesions but were instead related to regional volumes of the left pre-SMA and the cerebellum. A subgroup of basal ganglia subjects with additional frontal lesions showed impaired implicit learning of the visuo-motor sequence. These results may offer an explanation for the fact that in our study subjects with focal basal ganglia lesions as a whole did not have implicit learning deficits, whereas in previous studies on subjects with degenerative basal ganglia diseases (PD or HD), implicit learning deficits frequently occurred (Knopman and Nissen 1991; Ferraro et al. 1993; Pascual-Leone et al. 1993; Jackson et al. 1995; Doyon et al. 1997). In Parkinson's and Huntington's disease, the degenerative nature of both diseases makes it difficult to determine the extent to which basal ganglia and other brain structures, especially cortical areas, are affected at the time of testing. There is evidence from neuropathological studies that frontal cortical areas get involved early in the disease process (Kuhl et al. 1982; Vonsattel et al. 1985; Hornykiewicz and Kish 1986; Aylward et al. 1998). Implicit learning deficits in PD or HD subjects may thus result from the simultaneous disruption of striatal and frontal circuits.

We could not find evidence for the possibility that bilateral focal lesions of the basal ganglia might interrupt implicit motor learning (cf. Doyon et al. 1997). Two of our basal ganglia subjects had bilateral lesions; one of these subjects showed intact implicit learning, and the other subject, presenting also with lacunar frontal lesions, showed no signs of implicit learning on the SRTT (cf. Table 2). However, the data basis of only two subjects is too small to allow for a general conclusion.

Based on monkey studies, the supplementary motor area (Passingham 1993) and the most anterior portions of the caudate and putamen (Miyachi et al. 1997) were shown to be involved in motor sequence learning. The lesions of our subjects in all cases involved the head of the caudate
(Table 2), although not in its most anterior part. Therefore, we are not in the position to analyze whether anterior lesions of the striatum interfere with implicit motor sequence learning.

\section{Role of the Frontal Cortex and Cerebellum in Implicit Motor Learning}

The relationship we found between sequence-specific implicit learning and volume of the left pre-SMA in the basal ganglia group supports the notion that frontal areas, especially premotor areas, play an important role in implicit motor learning. This is the first time that a direct relationship between the size of a frontal area and implicit motor learning could be shown. We found the same relationship in schizophrenic subjects: Impaired implicit learning in the SRTT was related to smaller pre-SMA volumes (C. Exner, K. Boucsein, D. Degner, and E. Irle, in prep.). This relationship between size of the pre-SMA and implicit learning is consistent with present neural models of implicit motor learning. The involvement of sensorimotor and supplementary motor cortex in implicit motor learning was indicated by lesion and functional imaging studies (Grafton et al. 1995; Ackermann et al. 1996; Hazeltine et al. 1997; Grafton et al. 1998; Gomez Beldarrain et al. 1999). There is now a consensus that the SMA may be divided into two cytoarchitectonically and functionally different areas (Rizzolatti et al. 1996). The anterior part of the SMA is known to play a role in the more complex, planning and decision components of movements (Marsden et al. 1996). Lesions in this area especially compromise self-directed (voluntary) sequential actions in human and nonhuman primates (Halsband et al. 1993; Passingham 1993). PET results indicate that pre-SMA might especially support the anticipatory preparation of movements guided by internal cues (Deiber et al. 1991). The anticipatory direction of visual attention and preparation of the next expected movement are thought to form important processes involved in sequence-specific implicit learning of a visuo-motor sequence. The role of the premotor cortex, especially the anterior supplementary motor area, in motor sequence learning might thus be seen in the capacity to use redundancy in the stimulus and response sequence for the direction of visual attention toward the next expected stimulus and the preparation of the next required movement.

Apart from the left pre-SMA volume, the cerebellar volume of basal ganglia subjects was also significantly related to sequence-specific implicit learning. Previous studies reported deficiencies of subjects with neurodegenerative cerebellar pathology (Pascual-Leone et al. 1993; Doyon et al. 1997) or focal vascular cerebellar lesions (Molinari et al. 1997; Gomez Beldarrain et al. 1998) in implicit motor learning of a repeating sequence independent of motor impairment. Functional imaging studies have further confirmed cerebellar involvement in motor sequence learning (Rauch

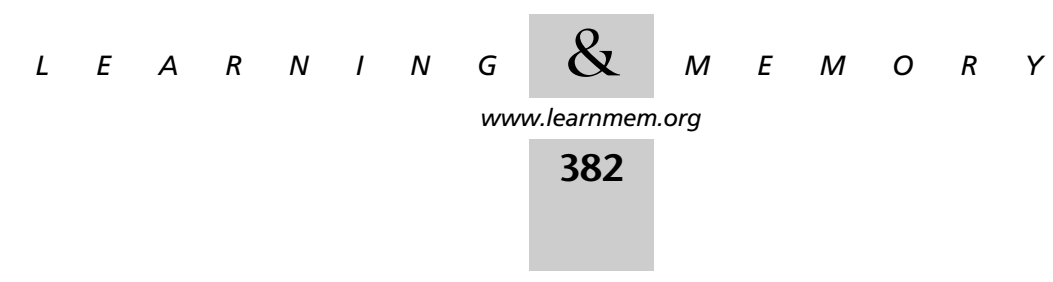


et al. 1995; Doyon et al. 1996). Lesion studies in primates showed that following bilateral cerebellar lesions, monkeys failed to acquire reaction-time gains in response to predictable visual stimuli. It thus appears that the function of the cerebellum in motor learning is to prepare responses to predictable sensory events (Nixon and Passingham 2001).

\section{Conclusions for Network Models of Motor Sequence Learning}

Procedural learning is now modeled as a process supported by a network of frontal cortical, striatal, and cerebellar areas (Willingham 1998). Functional imaging studies of implicit motor sequence learning have further supported the view that implicit sequence learning is achieved by the interaction of premotor cortical areas, basal ganglia, and cerebellum (Grafton et al. 1995; Rauch et al. 1995; Doyon et al. 1996; Hazeltine et al. 1997; Rauch et al. 1997; Honda et al. 1998). On the basis of our results, one could therefore speculate that lesions restricted to only one element of this network are not sufficient to disrupt implicit learning. If basal ganglia impairment is extended into frontal cortical areas as was the case in some of our subjects and as will frequently happen in Parkinson's disease and Huntington's disease, the deficit can no longer be compensated for by the organisms. Similar effects for the area of declarative learning have been reported in subjects with ruptured aneurysms of the anterior communicating artery: memory deficits occurred only in subjects with combined lesions of the striatum and the basal forebrain. Lesions restricted to only one of these structures did not result in memory impairment (Irle et al. 1992).

What might be the exact contribution of the premotor cortex, the basal ganglia, and the cerebellum in such a proposed network is still a matter of conjecture. The present evidence indicates that whenever movements are performed, planned, or imagined, the basal ganglia facilitate the required movements to secure smooth running of motor actions (for review, see Brooks 2000). In serial reactiontime learning they might support general adjustment to the new motor requirements of the task via, for example, stimulus-response matching, response selection, and shifting between alternative response sets. In contrast to the more general role of the basal ganglia in adapting motor response learning of specific stimulus associations in sequence-specific learning, they may chiefly depend on the cortex, that is, the prefrontal and motor cortex, whose activity underlies processes of directed visual attention and working memory (Harrington et al. 2000), and the sensorimotor cortex, which might be the site for the neural representation of specific sequential movements (Karni et al. 1998). Leiner et al. (1991) propose on the basis of the internal organization of the cerebellum and its anatomical connections that it may have a general role in promoting adaptive behavior acting as an adaptive mechanism that can improve different motor and nonmotor skills.

\section{MATERIALS AND METHODS}

\section{Subjects and Study Design \\ Group 1 (Basal Ganglia)}

Twenty subjects with ischemic or hemorrhagic lesions restricted to the basal ganglia were studied (Table 1). Subjects were identified by screening the CT- and MRT-results records of the neurological department of the University of Göttingen (1995-1997). Subjects older than 70 years, with a mother tongue other than German, or with a history of psychiatric or other neurological disease were excluded. Those who matched study criteria (a total of 54 subjects) were asked for participation, and 17 men and 3 women ranging from 20 to 68 years of age participated in this study. Subjects were assessed at least 6 mo after onset of stroke symptoms.

\section{Group 2 (Controls)}

The lesioned subjects were compared with 20 healthy control subjects recruited for the study by an advertisement in a local newspaper and leaflets distributed in the hospital and in town. Only subjects without a history of psychiatric or neurological disease were studied. Control subjects were paid for their participation and matched subjects in group 1 in terms of age, sex, and years of education.

After complete description of the study to the subjects, informed consent was obtained. The Ethical Committee of the Medical Faculty of the University of Göttingen had approved of the study design.

\section{Clinical Investigations}

All basal ganglia subjects underwent a neurological examination that comprised motor, sensory, visual, cerebellar, vestibular, reflex, and cranial nerve function (see Table 1). Then 16 subjects of the basal ganglia group and 13 controls received a $T_{1}$-weighted MR scan using a 1.5-T Philips Gyroscan machine at the day of the assessment. Two subjects of group 1 could not receive an MR scan because they had pacemakers. Two subjects of group 1 refused to have an MR scan performed because of claustrophobia. Lesion analysis in these 4 subjects was therefore based on CT and MRT scans that had been performed earlier.

\section{Neuropsychological Assessment}

All subjects underwent a comprehensive neuropsychological evaluation. The results are reported in Exner et al. (2001). The two study groups did not differ with regard to full-scale IQ (WAIS-R: Wechsler Adult Intelligence Scale-Revised; Table 1).

\section{MRI Acquisition}

Subjects of the two study groups received an MR scan using a 1.5-T Philips Gyroscan machine at the day of the assessment. The scanning parameters of the $T_{1}$-weighted three-dimensional sequence were as follows: echo time $(\mathrm{TE})=6.0 \mathrm{msec}$; repetition time $(\mathrm{TR})=24.05 ;$ number of excitations $(\mathrm{NEX})=2$; flip angle $=30^{\circ}$; field of view $(\mathrm{FOV})=256$; slice plane $=$ sagittal; matrix $=256 \times 256$; slice thickness $=1-1.3 \mathrm{~mm}$; slice number $=130$ 180 ; acquisition mode $=3 \mathrm{D}$.

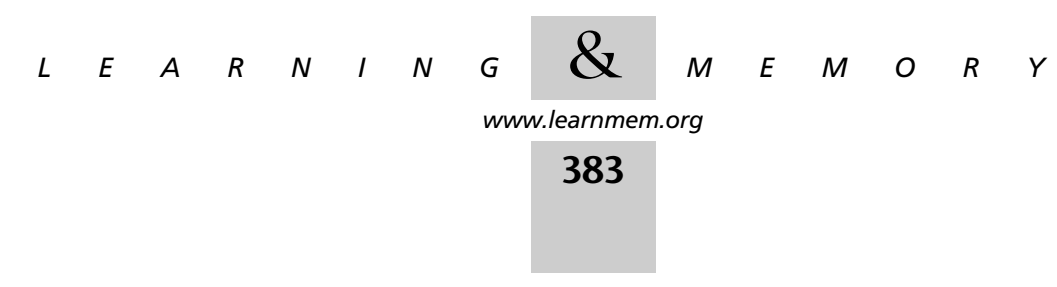




\section{Image Processing}

Volumetric analysis was done on the basis of 3D MR images. The images were transferred to a computer workstation and processed using the CURRY software (version 4.5; Neurosoft, Inc.). Images were reformatted into continuous slices of $1-\mathrm{mm}$ thickness. 3D region growing methods that are limited by gray value (i.e., = cortex) thresholds were used to determine the total brain volume, as well as the volume of the cerebellum and of the supplementary motor area (SMA).

\section{Defining Regions of Interests (ROIs) \\ Cerebellum}

The anterior border was defined by a vertical plane at the most anterior point of the cerebellum. Manual markings were then made on each coronal slice to separate the cerebellum from supratentorial structures, brain stem, and pons.

\section{Supplementary Motor Area (SMA)}

See Figure 2B for details of region parcellation. The SMA area was divided into a rostral (pre-SMA) and a caudal part (SMA-proper) as described for the human brain by Zilles et al. (1996). We used sulcal landmarks for the delineation of the boundaries of the SMA when possible, as sulcal landmarks have the advantage to directly model the substantial interindividual morphological variability of the human cerebral cortex (Rademacher et al. 1992). The anterior border of the pre-SMA was defined by a plane vertical to the AC-PC line and touching the inner surface of the corpus callosum. A vertical line passing through the paracentral frontal sulcus (PaCS) defined the posterior border of the pre-SMA and the anterior border of the SMA-proper. The PaCS is defined as the sulcus on the medial cortical surface being situated nearest and posterior to a vertical line that passes through the anterior commissure (Crespo-Facorro et al. 1999). The posterior border of the SMA-proper was defined by a vertical line passing through the medial part of the precentral sulcus (PCS).

It is difficult to define the boundaries of the SMA on the lateral surface of the superior frontal gyrus. Therefore, manual markings were made on coronal slices by drawing a straight line from the superior frontal sulcus to the cingulate sulcus. The resulting volume includes pre-SMA (BA 6aß), SMA-proper (BA 6a $\alpha$ ), small aspects of the laterally adjacent premotor cortex (lateral BA $6 \mathrm{a} \alpha$ ), as well as anterior (BA 24c) and posterior (BA 24b) cingulate motor areas (Zilles et al. 1996).

\section{Lesion Analysis and Lesion Groups}

Lesion analysis was also done on the basis of 3D MR images. Lesion territories of basal ganglia lesions were localized by E.I., who was unaware of the results of the behavioral assessments using the atlas of Mai et al. (1997). Lesion areas were mapped onto appropriate templates, and involvement of basal ganglia subregions was assessed. Areas covered by the lesion were calculated in each slice using a standard grid; areas were summed across slices and multiplied by slice thickness, resulting in approximate lesion volume.

Lesion analysis confirmed lesions in the basal ganglia in all 20 subjects (see Table 2 for details and Fig. 1 for an example). Seven subjects also demonstrated lacunar lesions in frontal motor areas (Brodman areas 4 and 6 including the supplementary motor area). The basal ganglia group was therefore divided into two subgroups: group 1A contained subjects with lacunar lesions in frontal motor areas (see Fig. 2A), and group 1B contained subjects without such lesions.

\section{Reliability of Lesion Analysis and Volumetric Measures}

All analyses were done blind to subjects' test performance. Re-test reliability was established for basal ganglia lesion mapping. Re-test reliability was 0.86 with regard to size of lesion.

Parcellations of the SMA as well as estimation of cortex thresholds were done by a well-trained rater (E.I.). For defining the intrarater reliability, one hemisphere of 11 randomly chosen cases was reassessed by the analyst (E.I.). The intraclass correlation coefficient for this procedure was $r=0.97$.

\section{Serial Reaction Time Task (SRTT) \\ Stimuli and Apparatus}

We used a variation of the serial reaction-time test designed by Nissen and Bullemer (1987). An asterisk appeared in one of four positions that were horizontally spaced on a computer screen and permanently marked by dots. The subjects were instructed to press the key corresponding to the position of the asterisks as fast as possible using their middle and index fingers of right and left hands. The response-to-stimulus interval was $300 \mathrm{msec}$. The test consisted of 8 blocks of 120 trials. In blocks 1 and 6 , the sequence of asterisks followed a pseudorandom order in the way that asterisks were presented equally frequent in each position and never in the same position on two subsequent trials. In blocks 2 to 5 , the same 12-trials sequence of asterisk positions repeated itself 10 times (abadbcdacbdc). Blocks 7 and 8 again contained the sequence to prevent interference with the random series before subjects' explicit knowledge was tested. After performing the reactiontime task, subjects were told that there had been a fixed sequence of asterisk positions and were submitted to a free generation task. We asked subjects to reproduce the sequence by pressing the buttons in the same order as they thought they did before (manual recall). The task ended after 60 self-generated trials.

\section{Data Analysis}

Incorrect responses and reaction times of $<200 \mathrm{msec}$ or $>3000$ msec or those that were above 3 standard deviations of the individual subject's mean response time were discarded (mean discarded trials in the basal ganglia group: $4.1 \%$; in the control group: 4.6\%). The only measure analyzed was reaction time because the number of errors made by the subjects was negligible and did not follow a special pattern across blocks of trials. Mean reaction times were calculated for each block of trials. Subjects' performance in the task was characterized by the following variables:

1. The reaction time difference between block 6 and block 5 was regarded the dependent variable of sequence-specific implicit learning.

2. The difference between the random blocks 1 and 6 was an indicant of general reaction-time improvement independent of sequence-specific learning.

3. Subjects' explicit knowledge of the repeating sequence was judged from subjects' responses in the free generation task. To prove whether subjects' inputs in this free generation task reflected true explicit knowledge of the repeating sequence, the random level had to be determined. For this, 15 volunteers who had not performed the SRTT were asked to randomly press the four response keys 60 times, producing whatever sequences they wanted. These random sequences were then compared to the repeating sequences that were used in the SRTT, yielding a

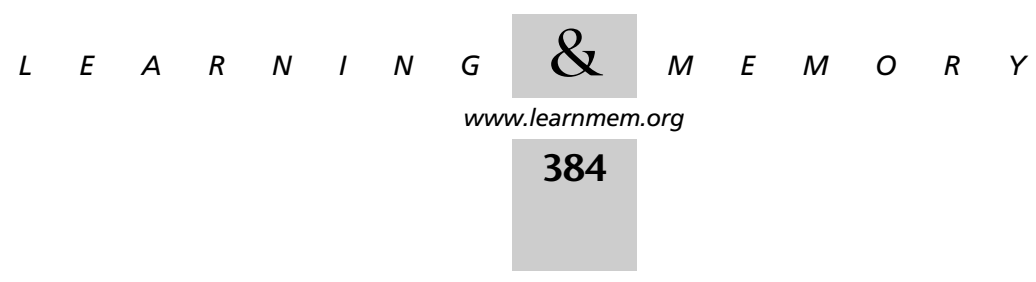


random level to which the explicit knowledge scores of the study groups could be compared.

\section{Statistical Analysis}

Statistical computations were based on scaled scores (WAIS-R) or raw scores. One-way ANOVAs and $t$-Tests were applied where appropriate to compare differences between groups. We used nonparametric tests to analyze data in case of unequal variances or small subject numbers. Multivariate comparisons were performed using a nonparametric version of the classical mixed model (Akritas and Brunner 1997). Frequencies were compared using the $\chi^{2}$ test or Fisher's exact test in case of expected frequencies below 5 . Partial correlations were calculated to examine the relationship between anatomical variables (size of lesions and regional volumes) and measures of implicit learning, controlling for total brain volume. All statistical comparisons were performed using the Statistical Package for the Social Sciences (SPSS for Windows, Version 9.0).

\section{ACKNOWLEDGMENTS}

We express our appreciation to all subjects who participated in this study. The authors further thank E. Koscholke, N. Arnold, and G. Weniger for their assistance in subjects' assessments. We thank T. Goschke, who wrote the computer programs for the SRTT, and J. Baudewig, who assisted with the processing of the MRI data. The study was supported by a grant from the Deutsche Forschungsgemeinschaft to E.I. (IR15/6-2).

The publication costs of this article were defrayed in part by payment of page charges. This article must therefore be hereby marked "advertisement" in accordance with 18 USC section 1734 solely to indicate this fact.

\section{REFERENCES}

Ackermann, H., Daum, I., Schugens, M.M., and Grodd, W. 1996. Impaired procedural learning after damage to the left supplementary motor area. J. Neurol. Neurosurg. Psych. 60: 94-97.

Akritas, M.G. and Brunner, E. 1997. A unified approach to rank tests for mixed models. J. Statis. Plan. Infer. 61: 249-277.

Aylward, E.H., Anderson, N.B., Bylsma, F.W., Wagster, M.V., Barta, P.E., Sherr, M., Feeney, J., Davis, A., Rosenblatt, A., Pearlson, G.D., et al. 1998. Frontal lobe volume in patients with Huntington's disease. Neurology 50: 252-258

Brooks, D.J. 2000. Imaging basal ganglia function. J. Anat. 196: 543-554.

Crespo-Facorro, B., Kim, J.J., Andreasen, N.C., O'Leary, D.S., Wiser, A.K., Bailey, J.M., Harris, G., and Magnotta, V.A. 1999. Human frontal cortex: An MRI-based parcellation method. NeuroImage 10: 500-519.

Deiber, M.-P., Passingham, R.E., Colebatch, J.G., Friston, K.J., Nixon, P.D., and Frackowiak, R.S.J. 1991. Cortical areas and the selection of movement: A study with positron emission tomography. Exp. Brain Res. 84: 393-402.

Doyon, J., Owen, A.M., Petrides, M., Sziklas, V., and Evans, A.C. 1996. Functional anatomy of visuomotor skill learning in human subjects examined with positron emission tomography. Eur. J. Neurosci. 8: 637-648

Doyon, J., Gaudreau, D., Laforce, R., Castonguay, M., Bédard, F., and Bouchard, J.-P. 1997. Role of the striatum, cerebellum, and frontal lobes in the learning of a visual sequence. Brain Cogn. 34: 218-245.

Exner, C., Weniger, G., and Irle, E. 2001. Implicit and explicit memory after focal thalamic lesions. Neurology 57: 2054-2063.

Ferraro, F.R., Balota, D.A., and Connor, L.T. 1993. Implicit memory and the formation of new associations in nondemented Parkinson's disease individuals and individuals with senile dementia of the Alzheimer type A serial reaction time (SRT) investigation. Brain Cogn. 21: 163-180.

Gomez Beldarrain, M., Garcia Monco, J.C., Rubio, B., and Pascual Leone,
A. 1998. Effect of focal cerebellar lesions on procedural learning in the serial reaction time task. Exp. Brain Res. 120: 25-30.

Gomez Beldarrain, M., Grafman, J., Pascual-Leone, A., and Garcia-Monco, J.C. 1999. Procedural learning is impaired in patients with prefrontal lesions. Neurology 52: 1853-1860.

Grafton, S.T., Hazeltine, E., and Ivry, R.B. 1995. Functional mapping of sequence learning in normal humans. J. Cog. Neurosci. 7: 497-510.

. 1998. Abstract and effector-specific representations of motor sequences identified with PET. J. Neurosci. 18: 9420-9428.

Halsband, U., Ito, N., Tanji, J., and Freund, H.-J. 1993. The role of premotor cortex and the supplementary motor area in the temporal control of movement in man. Brain 116: 243-266.

Harrington, D.L., Rao, S.M., Haaland, K.Y., Bobholz, J.A., Mayer, A.R., Binder, J.R., and Cox, R.W. 2000. Specialized neural systems underlying representations of sequential movements. J. Cog. Neurosci. 12: $56-77$.

Hazeltine, E., Grafton, S.T., and Ivry, R. 1997. Attention and stimulus characteristics determine the locus of motor-sequence encoding. A PET study. Brain 120: 123-140.

Honda, M., Deiber, M.P., Ibanez, V., Pascual Leone, A., Zhuang, P., and Hallett, M. 1998. Dynamic cortical involvement in implicit and explicit motor sequence learning. A PET study. Brain 121: 2159-2173.

Hornykiewicz, O. and Kish, S.J. 1986. Biochemical pathophysiology of Parkinson's disease. In Advances in neurology, Vol. 45, Parkinson's disease (eds. M.D. Yahr and K.J. Bergmann), pp. 19-33. Raven Press, New York.

Irle, E., Wowra, B., Kunert, H.J., Hampl, J., and Kunze, S. 1992. Memory disturbances following anterior communicating artery rupture. Ann. Neurol. 31: 473-480.

Jackson, G.M., Jackson, S.R., Harrison, J., Henderson, L., and Kennard, C. 1995. Serial reaction time learning and Parkinson's disease: Evidence for a procedural learning deficit. Neuropsychologia 33: 577-593.

Karni, A., Meyer, G., Rey-Hipolito, C., Jezzard, P., Adams, M., Turner, R., and Ungerleider, L. 1998. The acquisition of skilled motor performance: Fast and slow experience-driven changes in primary motor cortex. Proc. Natl. Acad. Sci. 95: 861-868.

Knopman, D. and Nissen, M.J. 1991. Procedural learning is impaired in Huntington's disease: Evidence from the serial reaction time task. Neuropsychologia 29: 245-254.

Kuhl, D.E., Phelps, M.E., Markham, C.H., Metters, E.J., Riege, W.H., and Winter, J. 1982. Cerebral metabolism and atrophy in Huntington's disease determined by ${ }^{18}$ FDG and computed tomographic scan. Ann. Neurol. 12: 425-434.

Laforce, R. and Doyon, J. 2001. Distinct contribution of the striatum and cerebellum to motor learning. Brain Cogn. 45: 189-211.

Leiner, H.C., Leiner, A.L., and Dow, R.S. 1991. The human cerebro-cerebellar system: Its computing, cognitive, and language skills. Behav. Brain Res. 44: 113-128.

Mai, J., Assheuer, J., and Paxinos, G. 1997. Atlas of the buman brain. Academic Press, San Diego.

Marsden, C.D., Deecke, L., Freund, H.-J., Hallett, M., Passingham, R.E., Shibasaki, H., Tanji, J., and Wiesendanger, M. 1996. The function of the supplementary motor area. Adv. Neurol. 70: 477-487.

Mishkin, M., Malamut, B., and Bachevalier, J. 1984. Memories and habits: Two neural systems. In Neurobiology of learning and memory (eds. G. Lynch et al.), pp. 65-77. Guilford Press, New York.

Miyachi, S., Hikosaka, O. Miyashita, K., Karadi, Z., and Rand, M.K. 1997. Differential roles of monkey striatum in learning of sequential hand movement. Exp. Brain Res. 115: 1-5.

Molinari, M., Leggio, M.G., Solida, A., Ciorra, R., Misciagna, S., Silveri, M., and Petrosini, L. 1997. Cerebellum and procedural learning: Evidence from focal cerebellar lesions. Brain 120: 1753-1762.

Nissen, M.J. and Bullemer, P. 1987. Attentional requirements of learning: Evidence from performance measures. Cogn. Psychol. 19: 1-32.

Nixon, P.D. and Passingham, R.E. 2001. Predicting sensory events. The role of the cerebellum in motor learning. Exp. Brain Res. 138: 251-257.

Pascual-Leone, A., Grafman, J., Clark, K., Steward, M., Massaquoi, S., Lou,

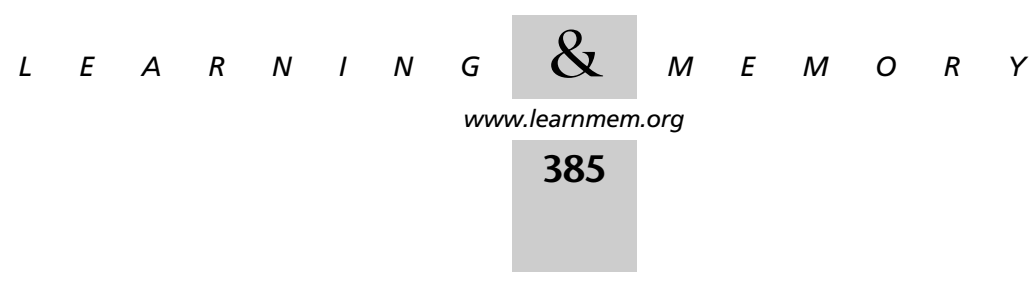


J.-S., and Hallett, M. 1993. Procedural learning in Parkinson's disease and cerebellar degeneration. Ann. Neurol. 34: 594-602.

Pascual-Leone, A., Grafman, J., and Halett, M. 1995. Procedural learning and prefrontal cortex. Ann. N.Y. Acad. Sci. 769: 61-70.

Pascual-Leone, A., Wassermann, E.M., Grafman, J., and Hallet, M. 1996 The role of dorsolateral prefrontal cortex in implicit procedural learning. Exp. Brain Res. 107: 479-485.

Passingham, R.E. 1993. The frontal lobes and voluntary action. Oxford University Press, Oxford.

Quinn, N.P., Rossor, M.N., and Marden, C.D. 1986. Dementia and Parkinson's disease-Pathological and neurochemical considerations. Br. Med. Bull. 42: 86-90.

Rademacher, J., Galaburda, A.M., Kennedy, D.N., Filipek, P.A., and Caviness, Jr., V.S. 1992. Human cerebral cortex: Location, parcellation, and morphometry with magnetic resonance imaging. J. Cog. Neurosci. 4: 352-374.

Rauch, S.L., Savge, C.R., Brown, H.D., Curran, T., Alpert, N.M., Kendrick, A., Fischman, A.J., and Kosslyn, S.M. 1995. A PET investigation of implicit and explicit sequence learning. Hum. Brain Mapp. 3: 271-286.

Rauch, S.L., Whalen, P.J., Savage, C.R., Curran, T., Kendrick, A., Brown, H.D., Bush, G., Breiter, H.C., and Rosen, B.R. 1997. Striatal recruitment during an implicit sequence learning task as measured by functional magnetic resonance imaging. Hum. Brain Mapp. 5: 124-132.

Rizzolatti, G., Luppino, G., and Matelli, M. 1996. The classic supplementary motor area is formed by two independent areas. Adv. Neurol. 70: 45-56.

Singh, J., Metz, J., Gabrieli, J.D.E., Willingham, D.B., Dooley, D., Jiang, M., Chen, C.-T., and Cooper, M. 1993. Changes in regional cerebral blood flow associated with a non-patterned procedural memory task. Proc. Abstr. Soc. Neurosci. 19: 1001.

Smith, J., Siegert, R.J., McDowall, J., and Abernethy, D. 2001. Preserved implicit learning on both the Serial Reaction Time Task and artificial grammar in patients with Parkinson's disease. Brain Cogn. 45: 378-391

Squire, L.R. 1987. Memory and brain. Oxford University Press, New York, Oxford.

Vonsattel, J.-P., Myers, R.H., Stevens, T.J., Ferrante, R.J., Bird, E.D., and Richardson, E.P. 1985. Neuropathological classification of Huntington's disease. J. Neuropathol. Exp. Neurol. 44: 559-577.

Willingham, D.B. 1998. A neuropsychological theory of motor skill learning. Psychol. Rev. 105: 558-584.

Zilles, K., Schlaug, G., Geyer, S., Luppino, G., Massimo, M., Qu, M., Schleicher, A., and Schormann, T. 1996. Anatomy and transmitter receptors of the supplementary motor areas in the human and nonhuman primate brain. Adv. Neurol. 70: 29-43.

Received March 12, 2002; accepted in revised form September 4, 2002.

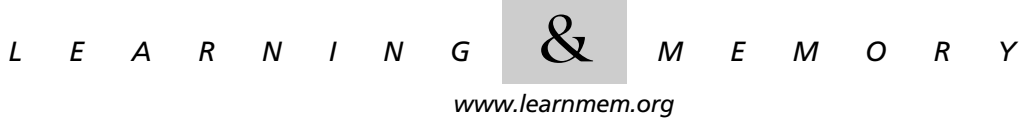




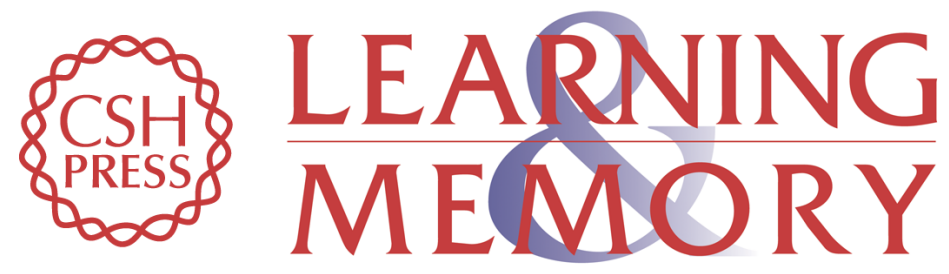

\section{The Differential Role of Premotor Frontal Cortex and Basal Ganglia in Motor Sequence Learning: Evidence From Focal Basal Ganglia Lesions}

Cornelia Exner, Janka Koschack and Eva Irle

Learn. Mem. 2002, 9:

Access the most recent version at doi:10.1101//m.48402

References This article cites 39 articles, 6 of which can be accessed free at: http://learnmem.cshlp.org/content/9/6/376.full.html\#ref-list-1

License

Email Alerting

Receive free email alerts when new articles cite this article - sign up in the box at the top Service right corner of the article or click here. 